\title{
Fiscalização de contratos de serviços terceirizados: desafios para a universidade pública
}

\section{Contract inspecting of outsourced service: challenges for public universities}

\author{
Rita de Cassia Pinto Marinho ${ }^{1}$ \\ Emmanuel Paiva de Andrade ${ }^{1}$ \\ Cassia Regina Pinto Marinho' ${ }^{1}$ \\ Elisabeth Flávia Roberta Oliveira da Motta ${ }^{1}$
}

\begin{abstract}
Resumo: A fiscalização de contratos na administração pública, conquanto fundamental para o bom funcionamento dos projetos e programas, não tem merecido o mesmo cuidado e suporte dispensado aos processos licitatórios. Os fiscais de contrato não constituem propriamente um grupo organicamente estruturado e isso dificulta a utilização do treinamento convencional. O papel do fiscal de contratos nas universidades públicas requer habilidades e conhecimentos heterogêneos, incluindo o domínio da legislação e práticas operacionais voltadas à manutenção de uma política de gestão eficiente que satisfaça o interesse público. Este artigo investiga os desafios enfrentados pelos profissionais e analisa os mecanismos de aprendizagem associados à atividade fiscalizatória. A ferramenta metodológica adotada baseia-se na estratégia do estudo de caso, utilizando entrevista estruturada e análise documental. Os resultados apontam a existência de fragilidades no processo de fiscalização, evidenciando a necessidade de aperfeiçoamento e desenvolvimento de competências dos agentes públicos designados a monitorar os contratos de serviços terceirizados na universidade pesquisada.
\end{abstract}

Palavras-chave: Gestão do conhecimento; Aprendizagem organizacional.; Administração pública.

\begin{abstract}
Contract inspecting in public management, albeit essential for the proper operation of projects and programs, have not been given the same care and support other bidding procedures have. The contract inspectors are not an organically-structured group, and this hinders the utilization of conventional training. The role of contract inspectors in public universities requires heterogeneous skills and knowledge, including thorough knowledge of legislation and operational practices of maintaining efficient management policies that satisfy the public interest. This paper investigates the challenges faced by these professionals and analyzes the learning mechanisms associated to the inspecting activity. The methodological tool is based on the case study strategy, making use of structured interviews and document analysis. The results point to the existence of weaknesses in the inspection process, confirming the need to hone and develop the skills of public agents assigned to the monitoring of outsourced service contracts in the university in question.
\end{abstract}

Keywords: Knowledge management; Organizational learning; Public administration.

\section{Introdução}

A universidade pública brasileira vive a partir de 2007 um processo de expansão sem precedentes na sua história. Essa expansão trouxe desafios para os setores internos ligados ao planejamento, execução e contratação de serviços contínuos que, via de regra, envolvem grande número de trabalhadores terceirizados. A contratação desses serviços pela Administração Pública constitui uma tarefa especialmente complexa do ponto de vista do acompanhamento e monitoramento, seja pela própria atividade de fiscalização na fase de execução do ajuste, seja no cumprimento das legislações e normas trabalhistas, cujo não atendimento pode desencadear a responsabilização subsidiária do tomador de serviços (órgão público) (Vieira et al., 2010). Esses fatores levam a refletir sobre a necessidade de desenvolvimento e manutenção de uma política de gestão de contratos eficiente, pautada em variáveis que satisfaçam e atendam ao dinamismo atualmente exigido do setor público.

A legislação determina que nos contratos celebrados seja designado um servidor com a responsabilidade

\footnotetext{
${ }^{1}$ Escola de Engenharia, Universidade Federal Fluminense - UFF, Campus Praia Vermelha, Rua Passo da Pátria, 156, Bloco D, São Domingos, CEP 24210-240, Niterói, RJ, Brasil, e-mail: rita.marinho2010@gmail.com; emmanueluff@gmail.com; cassiamarinho72@yahoo.com; efromotta@gmail.com
} 
de acompanhar e fiscalizar a execução do termo, cabendo, portanto, ao órgão público dispor de capacitação adequada, tecnologia apropriada e ambiente político-organizacional que acolha as demandas de aperfeiçoamento de competências desse profissional (Almeida, 2009). Desenvolver ações que promovam a capacidade técnica dos fiscais constitui prioridade do ponto de vista da eficiência operacional, particularmente nesse momento de expansão em que se encontram as universidades públicas brasileiras.

Visando o cumprimento e a plena execução das avenças pactuadas, é papel da organização propor e incentivar a utilização de práticas inovadoras que possam auxiliar no controle e acompanhamento do instrumento contratual (Battaglio \& Ledvinka, 2009). Sob essa perspectiva, o monitoramento dos termos representa, atualmente, um dos principais desafios na esfera pública, já que o registro de informações e a gestão do conhecimento, considerados elementos de suporte à construção de um ambiente interativo e inovador, constituem práticas ainda pouco adotadas entre os agentes públicos designados para o desempenho da função. Nesse sentido, torna-se fundamental que a organização implemente ações direcionadas à conversão do conhecimento, visando atingir um efetivo aprendizado organizacional e melhorar a eficiência no monitoramento dos ajustes pactuados.

Diante do exposto, o presente estudo, visando ampliar o debate em torno dessa temática ainda pouco explorada no ambiente da academia e que impacta significativamente sobre os resultados operacionais da universidade, tem como objetivo investigar os principais desafios e dificuldades que interferem no exercício da função dos fiscais de contratos, realçando a necessidade de desenvolvimento de competências profissionais e identificando mecanismos de aprendizagem associados à atividade fiscalizatória.

\section{Contratos de serviços terceirizados na Administração Pública}

O poder público formaliza a execução indireta dos serviços contínuos mediante assinatura de contrato administrativo que constitui o instrumento legal que norteia e regulamenta o acordo de vontades pactuado entre as partes. Trata-se, portanto, de um ajuste contratual firmado entre a entidade pública e seus prestadores de serviços, devendo conter cláusulas claras e objetivas, capazes de definir o objeto, os direitos, as obrigações, encargos e responsabilidades das partes.

A terceirização de serviços na esfera pública brasileira se expandiu na década de 90 , após aprovação do Plano Diretor da Reforma do Aparelho do Estado deflagrada no governo do Presidente da República Fernando Henrique Cardoso. A reforma administrativa procurou, entre outros aspectos, reduzir o tamanho do
Estado, mantendo sob sua responsabilidade apenas as atividades presumidamente típicas e exclusivas, transferindo às empresas privadas, mediante contratos de serviços, a execução de atividades consideradas acessórias à missão estatal (Freitas \& Maldonado, 2013).

Atualmente, o processo de terceirização é uma realidade na Administração Pública e para obter sucesso nesse modelo de gestão é importante dispor de um acompanhamento e monitoramento mais eficiente dos contratos firmados com os parceiros, no intuito de estimular o seu efetivo controle e garantir maior qualidade dos serviços prestados (Gonçalves, 2006; Pinto, 2009; Almeida, 2009; Vieira et al., 2010).

\subsection{Gestão e fiscalização de contratos administrativos}

Compete ao órgão público a tarefa de fiscalizar e acompanhar a prestação de serviços terceirizados, desde o monitoramento da execução contratual a nível operacional até a verificação do cumprimento, pela empresa contratada, dos direitos trabalhistas, previdenciários e fiscais resultantes da execução do contrato.

De acordo com Vieira et al. (2010), a fiscalização tem como base o acompanhamento físico do contrato, que deve ser realizado diariamente, in loco. Em um contexto mais abrangente, os autores definem a gestão do contrato como o acompanhamento das normas legais, análise da viabilidade de alteração contratual (por meio de repactuação, reequilíbrio econômico-financeiro); além da conferência dos documentos comprobatórios de situação regular junto ao INSS e FGTS, com o intuito de evitar condenação subsidiária da administração pública pelo não adimplemento das obrigações trabalhistas por parte da empresa terceirizada.

Abordagem similar é apresentada por Alves (2004), ao caracterizar que as ações de gestão não se confundem com as ações de fiscalização, pois a gestão cuida dos aspectos formais da contratação, enquanto a fiscalização se fixa no acompanhamento da execução do objeto contratual.

Portanto, a gestão é o serviço de gerenciamento das avenças que pode ser exercido por um servidor ou setor; já a fiscalização é exercida necessariamente por um agente público designado que cuidará pontualmente de cada contrato. Em uma situação ideal, é recomendável a segregação de funções, evitando que as atribuições e competências sejam realizadas por um mesmo responsável, embora essa excepcionalidade não seja vedada em lei (TCE-MT, 2015).

Conforme estabelece a Lei 8.666/93 (Brasil, 1993) - Lei de Licitação e Contratos - o órgão público e a empresa terceirizada devem indicar representantes, 
com perfis apropriados, para desempenhar atribuições inerentes às atividades de acompanhamento e execução do termo contratual. Enquanto a entidade pública designa um fiscal de contrato, a contratada elege um preposto. O preposto é a pessoa a quem o fiscal irá se reportar, repassando toda e qualquer irregularidade observada e recomendando as medidas saneadoras diante das inconformidades identificadas durante a vigência do instrumento contratual.

\section{Atribuições do fiscal de contratos administrativos}

Deficiência e ausência de fiscalização, rotineiramente, são apontadas como as principais causas de prejuízos à correta operacionalização de licitações e contratos administrativos, fato que ressalta a relevância da questão e fortalece a necessidade de atuação junto aos agentes que acompanham a execução contratual. A dificuldade de manter o quadro de pessoal com funcionários devidamente capacitados para desempenhar todas as prerrogativas exigidas pela legislação, bem como a falta de estrutura das diferentes unidades administrativas, tornam a questão da fiscalização o ponto mais vulnerável dos contratos administrativos e contribuem para uma conduta, muitas vezes, pouco eficiente dos agentes públicos.

Com o objetivo de regulamentar e auxiliar a atividade de fiscalização do instrumento contratual, o Ministério do Planejamento, Orçamento e Gestão publicou a Instrução Normativa ${ }^{\circ}$. 02/2008 (Brasil, 2008) e posteriores alterações que disciplinam a contratação de serviços continuados ou não na Administração Pública. As normas estabelecem diretrizes importantes para o acompanhamento dos contratos firmados entre o setor público e as empresas terceirizadas, visando garantir uma melhor atuação dos fiscais junto às prestadoras de serviços.

As ações do fiscal são predominantemente operacionais, tendo, no entanto, forte conteúdo cognitivo, nas quais o representante da Administração Pública precisa estar constantemente atento a diversas situações para imediatamente tomar as providências coercitivas, o que reforça a necessidade de um acompanhamento criterioso, pautado em parâmetros objetivos que possam auxiliar na plena execução contratual (Gonçalves, 2006).

O cenário sinaliza a necessidade de intervenções e nos remete a uma reflexão acerca das responsabilidades associadas aos profissionais da área de fiscalização de contratos. $\mathrm{O}$ rol de atribuições do fiscal exige o desenvolvimento de competências individuais e específicas, objetivando o pleno desempenho da função e consequente alcance de melhores resultados. Sob esse prisma, a utilização de conceitos voltados à aprendizagem pode oportunizar a disseminação do conhecimento e favorecer o aprimoramento das habilidades dos fiscais de contratos.

\section{Importância do conhecimento no desenvolvimento de competências}

O conhecimento é tratado como recurso ou capacidade prioritária para a criação de valor institucional, viabilizando resultados como estratégia, inovação e desempenho (Cherman \& Rocha-Pinto, 2016). Destaca-se como principal fundamento das competências essenciais de uma organização, requerendo a adoção de práticas gerenciais compatíveis e estimuladoras da criatividade e aprendizado individual. Por outro lado, o conceito de competências pode ser definido como um conjunto de conhecimento tácito e explícito, fruto das várias interações existentes no ambiente organizacional e do processo de aprendizagem, tomado como referência para a estratégia organizacional (Vera \& Crossan, 2005; Santos et al., 2012).

Vários autores trouxeram suas contribuições para o debate teórico sobre o tema e ampliaram o escopo das discussões. Durand (1998) salienta que o desenvolvimento da competência se configura por meio da aprendizagem individual e coletiva, com o envolvimento simultâneo de três dimensões (conhecimentos, habilidades e atitudes). Essas dimensões, interdependentes, são classificadas como os três pilares da competência.

Fleury \& Fleury (2001) também defendem um modelo conjugando aspectos individuais e organizacionais. Reforçam que a organização, inserida em um ambiente de forte competitividade, planeja suas estratégias e, paralelamente, as competências necessárias para atingi-las, as quais devem ser pautadas em um processo de aprendizagem permanente dos profissionais.

Lopes et al. (2010) comentam que, para atingir os objetivos estratégicos, a organização deve se preocupar com a gestão do capital intelectual no sentido de captar e utilizar todos os conhecimentos e competências de seus colaboradores. Muitas vezes essas competências podem estar dispersas fisicamente, embora presentes no imaginário de algumas categorias de trabalhadores dentro do que se convencionou chamar comunidades de prática. Brown \& Duguid (1991) chamam a atenção para o caráter de interpretação do conhecimento que tais comunidades constituem. Segundo eles, “[...] é através do contínuo desenvolvimento dessas comunidades que os significados comuns para interpretar atividades complexas são formados, transformados e transmitidos". Serenko \& Bontis (2016) acrescentam que a efetividade do compartilhamento do conhecimento depende de condições prévias que norteiam os propósitos da troca, isto é, condições de negociação, de reciprocidade ou de cooperação. 
Percebe-se entre os estudiosos uma rica variedade de abordagens caracterizada sob diferentes níveis de compreensão, o que evidencia a existência de correntes teóricas que relacionam o desenvolvimento de competências a um conjunto de conotações, ênfases e contextos vivenciados pelo indivíduo no ambiente laboral. Para enfrentar os desafios, o profissional se defronta com a necessidade de saber controlar a dinâmica organizacional e as situações inesperadas, de agir com responsabilidade, aplicando efetivamente seus conhecimentos, experiências e aprendizados adquiridos, a fim de desempenhar suas atividades com qualidade e criatividade.

Considerando que a aprendizagem organizacional, segundo Choo (2006), configura, junto com a administração da ambiguidade e a administração da incerteza, um dos três pilares da gestão do conhecimento, torna-se imprescindível a implementação de práticas que garantam o aprimoramento das rotinas e a qualificação dos profissionais, valendo-se dos recursos de transferência do conhecimento (Marinho \& Andrade, 2013b; Lemos \& Joia, 2012). Nessa perspectiva, Andrade et al. (2010) complementam que as organizações necessitam gerenciar o conhecimento utilizado em seus processos de forma eficiente e efetiva, visando promover o aprendizado organizacional e preservar seu capital intelectual. Picoli \& Takahashi (2016) entendem que o aprendizado exerce um papel fundamental na absorção do conhecimento pelas organizações.

Figueiredo (2009) ressalta a importância de examinar as relações acerca dos mecanismos que dão suporte à aprendizagem. Na visão do autor, recombinar e reconfigurar os ativos de conhecimento contribui para a sustentação da inovação e performance organizacional. O quadro 1 descreve as características dos processos, também intitulados mecanismos de aprendizagem intraorganizacional.

Os processos de aprendizagem estão dispostos em dois momentos distintos: aquisição e conversão do conhecimento. Os processos de aquisição do conhecimento favorecem o plano individual, permitindo a formação do denominado conhecimento tácito presente na mente dos profissionais. Por outro lado, os processos de conversão do conhecimento estão especialmente relacionados ao plano organizacional, avaliando como o conhecimento é disseminado no contexto institucional.

Para atingir um efetivo aprendizado organizacional é necessário estimular a integração entre os mecanismos de aprendizagem, e, para isso, torna-se fundamental que a organização implemente ações direcionadas tanto para o gerenciamento dos processos de aquisição quanto de conversão do conhecimento. A utilização de ferramentas de gestão do conhecimento surge como um importante recurso estratégico, por um lado permitindo a valorização dos saberes dos profissionais, por outro, possibilitando o estabelecimento de novas rotinas e práticas de trabalho em vários setores das organizações que precisam de reestruturação e, finalmente, quando ocorre em ambiente de terceirização, produzindo maior integração entre contratada e contratante e facilitando as ações de capacitação (Marinho \& Andrade, 2013a; Christopher \& Tanwar, 2012).

Em contrapartida, alguns autores têm revelado que o gargalo para a aplicação das práticas de gestão do conhecimento na relação com empresas terceirizadas reside, muitas vezes, na pouca capacitação delas com relação aos processos da $\mathrm{GC}$, incluindo a criação, transferência, integração e uso do conhecimento (Liu \& Deng, 2015; Easterby-Smith \& Prieto, 2008). Para Oliveira \& Villardi (2012), a questão da aprendizagem coloca desafios extras de urgência e profundidade quando se tratam das organizações públicas, uma vez que essas precisam se adaptar mais rapidamente ao contexto de mudanças sociais, políticas, culturais e econômicas, em resposta à pressão estabelecida pela crise de legitimidade do Estado e pela própria legitimidade junto à sociedade. Aliado a isso, exige-se que essas entidades articulem, de forma sistemática e contínua, processos de aprendizagem que

Quadro 1. Processos/mecanismos de aprendizagem intraorganizacional.

\begin{tabular}{|c|c|l|}
\hline $\begin{array}{c}\text { Processos/mecanismos de aprendizagem } \\
\text { intraorganizacional }\end{array}$ & \multicolumn{1}{c|}{ Características } \\
\hline \multirow{2}{*}{$\begin{array}{c}\text { Aquisição do } \\
\text { conhecimento }\end{array}$} & Aquisição externa & $\begin{array}{l}\text { Mecanismos pelos quais os profissionais adquirem conhecimentos tácitos } \\
\text { e/ou codificados vindos de fora da empresa. Ex.: treinamento no exterior. }\end{array}$ \\
\cline { 2 - 3 } & Aquisição interna & $\begin{array}{l}\text { Mecanismos pelos quais os profissionais adquirem conhecimentos } \\
\text { tácitos ao exercerem diferentes atividades na empresa. Ex.: cumprindo } \\
\text { tarefas rotineiras ou aperfeiçoando processos. }\end{array}$ \\
\hline \multirow{2}{*}{$\begin{array}{c}\text { Conversão do } \\
\text { conhecimento }\end{array}$} & Socialização & $\begin{array}{l}\text { Mecanismos pelos quais os profissionais compartilham seu saber tácito. } \\
\text { Ex.: observações, reuniões, solução conjunta de tarefas, treinamento. }\end{array}$ \\
\cline { 2 - 3 } & Codificação & $\begin{array}{l}\text { Mecanismos pelos quais o saber tácito individual é expresso em } \\
\text { conceitos explícitos, de forma organizada e acessível, tornando-se mais } \\
\text { facilmente assimilável. Ex.: padronização de métodos, documentação, } \\
\text { seminários internos. }\end{array}$ \\
\hline
\end{tabular}

Fonte: adaptado de Figueiredo (2009). 
impliquem na institucionalização do conhecimento e no desenvolvimento de competências de seus agentes (Finger \& Brand, 2001; Figueiredo, 2009; Marinho $\&$ Andrade, 2013c).

A predisposição à mudança na cultura, pautada na gestão do conhecimento e valorização do capital humano, constituem aspectos relevantes no processo de modernização e inovação das organizações. Essas exigências estão postas tanto para as organizações de natureza privada quanto pública, as quais encontram, dessa forma, oportunidade de renovar seus processos de trabalho e promover a transferência do conhecimento entre as equipes (Rodriguez, 2010; Carvalho \& Gomes, 2012).

Práticas de gestão do conhecimento têm sido implementadas por órgãos e entidades da Administração Pública brasileira na tentativa de alcançar maior eficiência e melhoria na qualidade dos serviços prestados à sociedade. Entretanto, essa realidade ainda não é hegemônica entre os órgãos públicos, de acordo com estudos realizados pelo Instituto de Pesquisa Econômica Aplicada - IPEA (Batista, 2006). Batista (2006) investigou a situação das práticas de gestão do conhecimento em instituições federais de ensino superior (IFES) e constatou que o tema ainda se encontra em estágio inicial, não sendo classificado como prioridade para a maioria das áreas administrativas e de planejamento das instituições analisadas. Mudar o panorama atual constitui um desafio, mas também deve ser encarado como uma proposta de modernização por aquelas instituições públicas que desejam incorporar mecanismos capazes de promover a disseminação dos saberes entre os profissionais.

A modernização da esfera pública, quase sempre motivada pela necessidade de melhoria de performance, não se pode fazer, no entanto, à revelia dos aspectos culturais, políticos e motivacionais que são característicos dessa dimensão da organização do trabalho e da produção. Documento da OECD sobre modernização do setor público lembra da importância de se levar em consideração inúmeros fatores, além dos comportamentais, que precisam ser diagnosticados previamente, tais como liderança, planejamento estratégico, gestão, a questão orçamentária e as políticas de avaliação (OECD, 2004). Dentre as atividades públicas que necessitam de intervenção modernizadora, destaca-se a área de fiscalização de contratos terceirizados nas universidades. Disponibilizar técnicas de gestão do conhecimento que atendam às necessidades da equipe de fiscais constitui uma forma viável de efetivar o adequado acompanhamento dos contratos, aprimorar as habilidades e motivar os níveis de comprometimento entre os profissionais, estabelecendo um ambiente institucional dinâmico e interativo. Nesse contexto, cabe aos administradores públicos das IFES intensificar o desenvolvimento de uma política interna de gestão do conhecimento efetivamente estruturada, capaz de mitigar deficiências existentes no campo da fiscalização e fomentar uma significativa mudança de cultura organizacional.

\section{Metodologia}

A pesquisa realizada adota, quanto a sua forma, uma abordagem predominantemente qualitativa (Vergara, 2007). Quanto ao delineamento foi utilizada a estratégia do estudo de caso, valendo-se de múltiplas fontes de investigação (Yin, 2005). Os dados foram coletados a partir de consultas em relatórios internos de gestão, registros eletrônicos, experiências observadas no cotidiano da instituição analisada e questionário semiestruturado. $\mathrm{O}$ estudo, de caráter aplicado e tipicamente de campo, permitiu identificar as principais fragilidades e desafios associados à atividade de fiscalização de contratos em uma universidade pública.

O acesso ao público alvo foi feito de maneira individual, com os pesquisadores se dirigindo ao ambiente de trabalho dos fiscais. A escolha dos participantes foi realizada por meio de um procedimento censitário, cujo critério para a composição da população foi o fato de o indivíduo estar desempenhando a função de fiscal de contratos de serviços terceirizados na instituição. A população foi composta por nove profissionais e, dentre eles, apenas um fiscal não demonstrou interesse em colaborar com a pesquisa, atingindo uma significativa taxa de retorno de $89 \%$.

Na etapa de coleta dos dados e posterior análise das percepções dos fiscais relacionadas às suas atribuições cotidianas, utilizou-se uma escala de resposta no modelo Likert, composta por cinco pontos, variando entre: (1) Nunca, (2) Raramente, (3) Eventualmente, (4) Frequentemente, (5) Sempre.

Posteriormente, para mensurar as ações consideradas essenciais e relevantes, as quais devem compor o rol de competências desses profissionais, as variáveis foram tratadas a partir de duas escalas do tipo Likert, seguindo proposta metodológica desenvolvida por Borges-Andrade \& Lima (1983).

Esse método permitiu o mapeamento do gap, ou lacuna de competências, estabelecendo a relação entre o domínio (por parte do profissional) de determinada competência e a importância dessa competência para o papel ocupacional (Carbone et al., 2009). Dessa forma foi possível traçar um diagnóstico de necessidades de aprendizagem, a partir da identificação do gap de competências, por meio da equação 1 :

$$
\text { IPT = IMP (4 - DOM })
$$

onde:

IPT $=$ índice de prioridade de treinamento $($ necessidade de aprendizagem $=$ gap $)$; 
IMP = variável que mede a importância de determinada competência - variando de 0 (nada importante) a 4 (extremamente importante);

DOM = variável que mede o domínio da competência - variando de 0 (não domina a competência) a 4 (domina plenamente a competência).

De acordo com a equação, o gap pode variar de 0 a 16. Nela, quanto maior o gap, maior a necessidade de investimento em aprendizagem na competência julgada. Logo, o estudo buscou identificar as competências de maior deficiência e estabelecer prioridades em relação à capacitação e treinamento dos profissionais.

Para tabular os dados coletados na pesquisa de campo, utilizaram-se os recursos do aplicativo Microsoft Office Excel. Posteriormente, esses dados foram exportados para o programa estatístico SPSS (Statistical Package for Social Sciences) versão 13.0 para Windows, valendo-se de conceitos de estatística descritiva para interpretar e analisar o fenômeno em estudo.

A partir da coleta, tratamento e compilação dos dados, buscou-se extrair informações relevantes para, então, iniciar a etapa de análise, visando descrever o cenário pesquisado e diagnosticar a situação atual. Uma vez identificada a questão da aprendizagem organizacional como o núcleo central da fragilidade do sistema de fiscalização, adotou-se a investigação estruturada dos mecanismos de aprendizagem proposta por Figueiredo (2009) para mapear as condições atuais de capacitação institucional.

\section{Análise e discussão dos resultados}

\subsection{Cenário e caracterização da instituição em estudo}

O cenário da presente pesquisa foi uma instituição federal de ensino superior localizada no Estado de Minas Gerais. Trata-se de uma universidade pública que, além de incentivar a titulação de seu quadro docente, prioriza a formação e educação de seu corpo discente. A qualidade do ensino é reconhecida nacionalmente, sendo comprovada através dos bons resultados obtidos nos processos de avaliação realizados recentemente pelo Ministério da Educação e Cultura (MEC).

O crescimento institucional ocorrido nos últimos anos é notável, registrando o incremento do número de alunos, em decorrência da ampliação e criação de vagas em novos cursos. Segundo informações constantes nos relatórios administrativos da instituição pesquisada, identifica-se que no período de 2007 a 2013 o número de vagas oferecidas na graduação passou de 2.115 para 3.855 vagas, correspondendo a um aumento de aproximadamente $80 \%$. Em resposta às diretrizes do processo de expansão, iniciaram-se melhorias nas condições de infraestrutura e, para tanto, foram realizadas reformas e construção de espaços acadêmicos, incluindo salas de aula, laboratórios e bibliotecas, buscando o contínuo fortalecimento das atividades de ensino, pesquisa e extensão.

Ao contrário da grande reestruturação interposta na área acadêmica, o seu quadro de servidores técnico-administrativos, como ocorreu na maioria das universidades públicas, não acompanhou a evolução na mesma proporção do crescimento institucional. Considerando as restrições à realização de concursos públicos para cargos efetivos, a unidade em análise intensificou o processo de terceirização, estimulando a celebração de contratos de serviços contínuos, conforme exigências estabelecidas pelos órgãos de controle.

Ciente da responsabilidade quanto ao cumprimento dos vários dispositivos legais e na tentativa de manter um núcleo de suporte às atividades inerentes à fiscalização, a instituição criou, no final de 2006, um setor específico para o acompanhamento de contratos. A execução do objeto contratual, realizado in loco, fica sob a responsabilidade dos fiscais de contratos, os quais desempenham a função com dedicação, seriedade e empenho, apesar de demonstrarem algumas limitações e dificuldades no desenvolvimento da atividade, frente à rigorosa legislação que regulamenta o assunto.

\subsection{Contratos de serviços terceirizados celebrados}

Pelo fato de a criação do setor de contratos ter ocorrido formalmente no final de 2006, estipulou-se o ano de 2007 como o marco temporal inicial para a coleta das informações, as quais foram obtidas a partir de pesquisa documental envolvendo relatórios administrativos e arquivos eletrônicos disponíveis. A tabela 1 descreve os serviços de terceirização celebrados e a evolução do quantitativo de funcionários terceirizados entre os anos de 2007 e 2013.

Analisando-se a tabela 1, percebe-se um crescimento no número de funcionários terceirizados, que passaram de 476, em 2007, para 793, em 2013, o que representa um aumento de $66 \%$. Com o objetivo de realizar um estudo detalhado sobre as forças de trabalho presentes na instituição, comparou-se o número de terceirizados contratados com o quantitativo de servidores técnico-administrativos do quadro efetivo, tomando-se como referência o mês de dezembro de 2013. A tabela 2 apresenta a proporção entre as categorias em estudo:

Os dados registram uma relação significativa entre as categorias de trabalhadores: $62 \%$ são servidores técnico-administrativos ativos e $38 \%$, funcionários terceirizados. Nesse comparativo fica evidenciado que mais de um terço da força de trabalho da instituição é 
composta por terceirizados. O resultado encontrado sugere a necessidade do desenvolvimento de métodos eficientes, visando aprimorar o monitoramento e a fiscalização dos contratos pactuados com empresas terceirizadas.

\subsection{Perfil dos respondentes}

A primeira parte do questionário procurou identificar o perfil dos entrevistados, caracterizando-os através das variáveis: sexo, grau de escolaridade e experiência como fiscal, conforme ilustra a tabela 3:

Uma informação relevante extraída da tabela 3 refere-se ao tempo de experiência na função: $61 \%$ dos participantes da pesquisa relataram desempenhar a atividade de fiscalização há mais de quatro anos. $O$ resultado indica que os profissionais já atuavam na função à época da publicação da IN 02/2008, a qual disciplinou regras e procedimentos para a contratação de serviços continuados na esfera pública. Os outros $39 \%$, quando designados para a função, já iniciaram seus trabalhos à luz da legislação vigente, não sendo, portanto, surpreendidos pela alteração da instrução normativa.

\subsection{Percepção dos fiscais em relação às fragilidades operacionais}

Com a finalidade de mensurar as possíveis fragilidades operacionais ocorridas durante o acompanhamento da execução contratual, foram analisadas algumas das principais atribuições dos fiscais de contratos, apresentadas na seção 3 deste estudo. Os resultados mais expressivos da pesquisa são detalhados nas subseções 6.4.1 e 6.4.2.

\subsubsection{Confrontando as atribuições A1 e A2}

A figura 1 e a figura 2 refletem os percentuais apurados para as variáveis A1 e A2, a seguir definidas. Seu objetivo foi avaliar a atuação dos fiscais em relação aos registros de ocorrências e anotações de diligências durante o desempenho da função:

Tabela 1. Categorias de serviços de terceirização contratados por ano e quantitativo de funcionários terceirizados - marco temporal 2007-2013.

\begin{tabular}{|c|c|c|c|c|c|c|c|}
\hline \multirow{2}{*}{ Serviços terceirizados } & \multicolumn{7}{|c|}{ Ano } \\
\hline & 2007 & 2008 & 2009 & 2010 & 2011 & 2012 & 2013 \\
\hline Manutenção predial & & & $\mathbf{X}$ & $\mathbf{X}$ & $\mathbf{X}$ & $\mathbf{X}$ & $\mathbf{X}$ \\
\hline Apoio administrativo e operacional & & & & $\mathbf{X}$ & $\mathbf{X}$ & $\mathbf{X}$ & $\mathbf{X}$ \\
\hline Vigia & $\mathbf{X}$ & $\mathbf{X}$ & $\mathbf{X}$ & $\mathbf{X}$ & $\mathbf{X}$ & $\mathbf{X}$ & $\mathbf{X}$ \\
\hline Apoio técnico às ações culturais & & & & $\mathbf{X}$ & $\mathbf{X}$ & $\mathbf{X}$ & $\mathbf{X}$ \\
\hline Conservação e limpeza & $\mathbf{X}$ & $\mathbf{X}$ & $\mathbf{X}$ & $\mathbf{X}$ & $\mathbf{X}$ & $\mathbf{X}$ & $\mathbf{X}$ \\
\hline Apoio administrativo e técnico & & & $\mathbf{X}$ & $\mathbf{X}$ & $\mathbf{X}$ & $\mathbf{X}$ & $\mathbf{X}$ \\
\hline Vigilância armada & $\mathbf{X}$ & $\mathbf{X}$ & $\mathbf{X}$ & $\mathbf{X}$ & $\mathbf{X}$ & $\mathbf{X}$ & $\mathbf{X}$ \\
\hline Motorista e lavador de veículo & & $\mathbf{X}$ & $\mathbf{X}$ & $\mathbf{X}$ & $\mathbf{X}$ & $\mathbf{X}$ & $\mathbf{X}$ \\
\hline Controle e fiscalização de portaria & & $\mathbf{X}$ & $\mathbf{X}$ & $\mathbf{X}$ & $\mathbf{X}$ & $\mathbf{X}$ & $\mathbf{X}$ \\
\hline Serviços de alimentação & $\mathbf{X}$ & $\mathbf{X}$ & $\mathbf{X}$ & & & & \\
\hline Serviços de biblioteca & $\mathbf{X}$ & $\mathbf{X}$ & & & & & \\
\hline Suporte técnico em informática & $\mathbf{X}$ & $\mathbf{X}$ & & & & & \\
\hline Número de funcionários terceirizados/ano & 476 & 481 & 488 & 563 & 582 & 731 & 793 \\
\hline
\end{tabular}

Fonte: relatórios administrativos da instituição.

Tabela 2. Proporção entre categorias: Técnico-administrativos ativos x Terceirizados.

\begin{tabular}{lcc}
\hline \multicolumn{1}{c}{ Categoria } & Quantidade & Percentual \\
\hline Servidores técnico-administrativos ativos & 1.293 & $62 \%$ \\
Funcionários terceirizados & 793 & $38 \%$ \\
Total: & $\mathbf{2 . 0 8 6}$ & $\mathbf{1 0 0 , 0 0 \%}$ \\
\hline
\end{tabular}

Fonte: registros internos da instituição coletados no mês de dezembro de 2013.

Tabela 3. Perfil dos participantes da pesquisa.

\begin{tabular}{ccl}
\hline Sexo & \multicolumn{1}{c}{ Grau de escolaridade } & \multicolumn{1}{c}{ Experiência como fiscal } \\
\hline Predominância do sexo masculino & $87 \%$ possuem curso de especialização & $61 \%$ desempenham a atividade há \\
$(65 \%)$, contra 35\% do sexo feminino. & e 13\% possuem o ensino médio. & $\begin{array}{l}\text { mais de quatro anos e 39\% há menos } \\
\text { de quatro anos. }\end{array}$ \\
\hline
\end{tabular}


A partir da análise da variável A1 nota-se que os fiscais apresentam dificuldades no acompanhamento do nível de qualidade dos serviços prestados por empresas terceirizadas, seja por não realizarem os registros de forma sistemática, seja por não disporem de instrumentos eficientes que possam auxiliá-los no monitoramento da execução contratual. A variável A1 confirma que somente $12,5 \%$ dos entrevistados praticam essa atribuição frequentemente.

A fragilidade quanto ao registro das atividades acompanhadas pelos fiscais foi identificada também na variável A2, na qual muitos profissionais expressaram não possuir o hábito de se reportar formalmente ao preposto da empresa, quando da observação de faltas ou ocorrências verificadas durante a diligência. $\mathrm{Na}$ maioria das vezes, os problemas são repassados de forma verbal, não havendo registro em documento próprio. Essa prática inibe uma ação mais eficiente do órgão público junto à contratada, uma vez que somente a partir de registros das ocorrências torna-se possível comprovar as irregularidades, estabelecer prazos para a solução dos problemas apontados e justificar a aplicação de advertências ou outras penalidades cabíveis.

Ao confrontar as duas variáveis, fica evidente a fragilidade quanto aos registros de ocorrências ou

A1. Monitora, através de registros, o nível de qualidade dos serviços, sugerindo intervenções e correções.

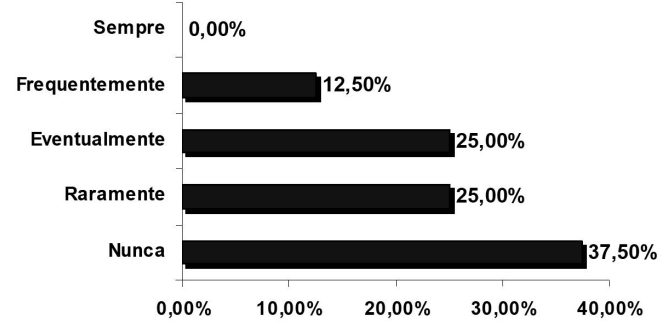

Figura 1. Frequência da variável A1.

Fonte: resultado da pesquisa.

A2. Dirige-se formalmente ao preposto da empresa, recomendando medidas saneadoras referentes a faltas e/ou ocorrências observadas.

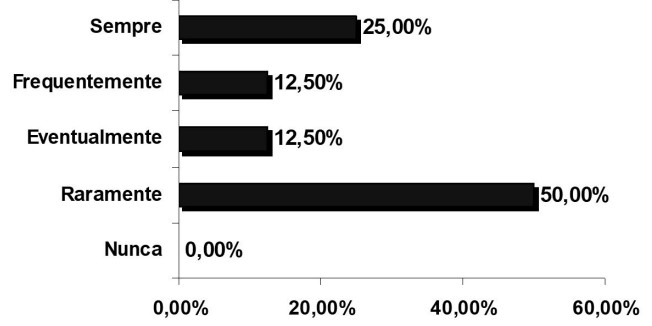

Figura 2. Frequência da variável A2.

Fonte: resultado da pesquisa. anotações de diligências realizadas pelos fiscais de contratos. Para reverter esse panorama, torna-se essencial o desenvolvimento de ações no sentido de disponibilizar mecanismos de aprendizagem que garantam maior controle dos ajustes pactuados com empresas terceirizadas, de modo a auxiliar a rotina de trabalho dos fiscais.

\subsubsection{Confrontando as atribuições A3 e A4}

Observada a vulnerabilidade quanto ao efetivo monitoramento dos contratos, buscou-se, em um segundo momento, analisar o comportamento dos fiscais em determinadas situações relacionadas aos trabalhadores terceirizados. A figura 3 e a figura 4 refletem os percentuais apurados para as variáveis A3 e A4, a seguir especificadas:

O acompanhamento da regularidade do pagamento de salários, adicionais e benefícios aos terceirizados representa uma importante ação atribuída aos fiscais. O não cumprimento da legislação e normas trabalhistas pode desencadear a responsabilização subsidiária da Administração Pública e a responsabilização administrativa do fiscal. Dessa forma, esse procedimento representa uma das mais relevantes ações que devem

A3. Verifica se a empresa terceirizada está efetuando regularmente o pagamento de salários, adicionais e benefícios aos seus funcionários.

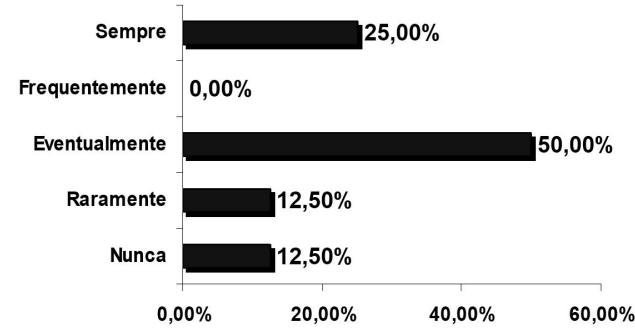

Figura 3. Frequência da variável A3. Fonte: resultado da pesquisa.

A4. Dirige-se diretamente ao terceirizado, determinando alterações na forma de prestação de serviços, quando julga necessário (alteração de horário, folga, local de trabalho).

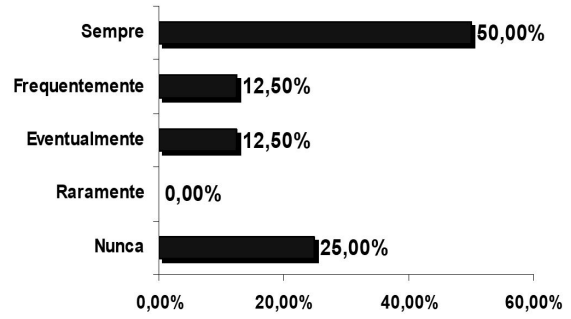

Figura 4. Frequência da variável A4. Fonte: resultado da pesquisa. 
ser constantemente monitoradas pelos agentes públicos. A partir da análise da variável A3, verifica-se que apenas $25 \%$ dos profissionais acompanham a regularidade do pagamento dos funcionários terceirizados, fato que traduz fragilidade no monitoramento e configura o despreparo dos fiscais frente às suas atribuições.

Se, por um lado, a legislação é rígida quanto ao acompanhamento das obrigações trabalhistas, por outro proíbe qualquer tipo de interferência dos agentes públicos junto aos trabalhadores terceirizados, sendo essa atividade de total responsabilidade do preposto da empresa contratada. Com o objetivo de verificar o grau de interferência dos fiscais de contratos sob aspectos relacionados a alterações na forma de prestação de serviços envolvendo horário, local e folga dos terceirizados, foi analisada a variável A4, na expectativa de se avaliar o nível de ocorrência da ação. Apesar da impropriedade de dirigirem-se diretamente aos terceirizados para determinar-lhes as alterações de trabalho que julguem pertinentes, a maioria dos fiscais declararam que sempre ou frequentemente praticam essa ingerência. Nesse contexto observa-se a importância de capacitar os profissionais, visando inibir a prática de determinados procedimentos que venham a caracterizar ilicitude da terceirização na Administração Pública.

\subsection{Identificação das prioridades em aprendizagem}

No esforço de atingir uma análise mais aprofundada em relação às rotinas de trabalho realizadas pelos fiscais, buscou-se apurar as prioridades em aprendizagem para o melhor desempenho da função. Os entrevistados foram divididos em dois grupos, a fim de identificar diferenças de comportamento entre os agentes públicos que foram recentemente designados e os que estavam há mais tempo na função e, dessa forma, estabelecer uma comparação quanto ao nível de conhecimento desses profissionais frente às recomendações dispostas nas legislações vigentes. Os grupos foram delineados, conforme a seguir:

- Grupo A - fiscais com menos de 4 anos na função, constituído por 3 participantes; e

- Grupo B - fiscais com mais de 4 anos na função, constituído por 5 participantes.

$\mathrm{O}$ intervalo de quatro anos justifica-se em função da publicação da IN 02/2008 - importante marco regulatório que definiu regras e diretrizes para a contratação de serviços contínuos na esfera pública. Registra-se que, após a edição desse dispositivo, outras instruções normativas e portarias foram publicadas, visando implementar o citado instrumento legal, porém, diante da expressividade de ações constantes nessa legislação direcionadas à área de fiscalização de contratos, consagra-se a publicação da IN 02/2008 como marco temporal para a análise desta pesquisa.

As competências abordadas foram mensuradas pelos fiscais através de duas escalas de julgamento do tipo Likert, variando de 0 a 4, conforme já apresentado na seção de procedimentos metodológicos.

A partir do cruzamento dos resultados entre os critérios importância e domínio das competências foi possível apurar o Índice de Prioridade de Treinamento (IPT), no intuito de evidenciar as competências de maior gap.

A tabela 4 apresenta os valores da média $(\mu)$, mediana (Md), moda (Mo) e desvio-padrão $(\sigma)$ das

Tabela 4. Resumo estatístico: Média, Mediana, Moda, Desvio padrão - Critério Importância por grupo.

\begin{tabular}{|c|c|c|c|c|}
\hline \multicolumn{5}{|c|}{ IMPORTÂNCIA DAS COMPETÊNCIAS } \\
\hline Descrição das competências & Média $\mu$ & Mediana Md & Moda Mo & Desvio padrão $\sigma$ \\
\hline \multicolumn{5}{|c|}{$\begin{array}{l}\text { C1. Ter conhecimento das normas legais que regulamentam as contratações públicas e a fiscalização de contratos } \\
\text { de terceirização. }\end{array}$} \\
\hline Grupo A & 3,67 & 4 & 4 & 0,577 \\
\hline Grupo B & 3,80 & 4 & 4 & 0,447 \\
\hline \multicolumn{5}{|c|}{ C2. Ter conhecimento das atribuições e responsabilidades inerentes à função de fiscal de contratos. } \\
\hline Grupo A & 3,67 & 4 & 4 & 0,577 \\
\hline Grupo B & 3,80 & 4 & 4 & 0,447 \\
\hline \multicolumn{5}{|c|}{ C3. Ter conhecimento detalhado do contrato sob sua supervisão e das cláusulas nele estabelecidas. } \\
\hline Grupo A & 3,33 & 3 & 3 & 0,577 \\
\hline Grupo B & 4,00 & 4 & 4 & 0,000 \\
\hline \multicolumn{5}{|c|}{$\begin{array}{l}\text { C4. Registrar, em documento próprio, as irregularidades encontradas e as providências determinadas, decorrentes } \\
\text { do descumprimento das obrigações pactuadas em contrato. }\end{array}$} \\
\hline Grupo A & 3,67 & 4 & 4 & 0,577 \\
\hline Grupo B & 3,80 & 4 & 4 & 0,447 \\
\hline \multicolumn{5}{|c|}{$\begin{array}{l}\text { C5. Utilizar mecanismos de controle (documentos padronizados) que possam auxiliar no acompanhamento dos } \\
\text { contratos. }\end{array}$} \\
\hline Grupo A & 3,33 & 4 & 4 & 1,155 \\
\hline Grupo B & 3,80 & 4 & 4 & 0,447 \\
\hline
\end{tabular}

Fonte: resultado da pesquisa. 
variáveis, sob o critério "Importância" considerando os dois grupos em estudo.

Analisando-se os valores atribuídos às medidas de tendência central na tabela 4 , identifica-se que todos os entrevistados, sejam integrantes do grupo A ou B, reconhecem a importância das competências elencadas, uma vez que todos os atributos, $\mu, \mathrm{Md}$ e Mo assumiram valores superiores a 3,00 (muito importante). A variabilidade também registrou valores bem baixos, confirmando a convergência de opiniões entre a maioria dos entrevistados.

Apresentadas as percepções dos fiscais quanto ao critério importância, iniciou-se o estudo em relação ao domínio de tais competências. A tabela 5 apresenta os valores da média $(\mu)$, mediana $(\mathrm{Md})$, moda $(\mathrm{Mo})$ e desvio-padrão $(\sigma)$ das variáveis, sob o critério "Domínio" considerando os dois grupos em estudo.

Diferentemente dos valores encontrados no critério importância, a tabela 5 registra valores mais baixos para os atributos de medidas de tendência central sob o critério domínio. Tanto no grupo A quanto no grupo $\mathrm{B}$, os valores das médias das variáveis são inferiores a 3,00, oscilando entre $\mu=1,00$ e $\mu=2,80$ (domina medianamente a competência). Os resultados da pesquisa revelam que, embora os fiscais reconheçam a importância das ações, existe uma deficiência quanto ao domínio das competências.

Particularmente em relação à moda, a tabela 5 registra valor "amodal" para três competências no grupo A. A ocorrência justifica-se pelo fato de esse grupo ser constituído por somente três fiscais, no qual cada um deles atribuiu um valor diferente para a competência analisada, não retornando, portanto, nenhum valor de moda para o item em julgamento.
Utilizando-se os valores das médias apuradas nas tabelas de importância e domínio foi possível fazer um diagnóstico das necessidades de aprendizagem, a partir da identificação do gap de competências, com o objetivo de avaliar as necessidades de treinamento frente algumas competências consideradas essenciais para o desempenho das atividades de fiscal de contratos.

A tabela 6 apresenta os índices médios apurados para o nível de treinamento em cada competência estudada e elenca o ranking daquelas atribuições que merecem maior capacitação. A competência que apresenta maior média de IPT indica maior gap, sendo classificada como primeiro lugar na coluna de ranking e assim sucessivamente.

Considerando-se que as médias de IPT variam de 0 a 16 foi estabelecido que as variáveis que apresentaram médias maiores que 8,00 correspondiam àquelas com maior prioridade de aprendizagem e treinamento. A seguir, o quadro 2 identifica as competências que precisam ser aprimoradas em cada grupo:

A partir das informações do quadro 2 verifica-se que apenas a competência $\mathrm{C} 3$ não foi assinalada em nenhum dos grupos, já que apresentou IPT menor que 8,00 e, de acordo com o critério adotado, não existe necessidade de oferecer treinamento para o item em julgamento, já que os profissionais revelaram possuir conhecimento detalhado das cláusulas contratuais. Entretanto, nas demais competências analisadas, a instituição deve oferecer ou proporcionar capacitação para os fiscais, sejam pertencentes ao grupo A ou B. Além do aprimoramento das competências, é importante também que o órgão incentive outras ações de conversão do conhecimento, de maneira que os fiscais mais antigos tenham condições de compartilhar suas

Tabela 5. Resumo estatístico: Média, Mediana, Moda, Desvio padrão - Critério Domínio por grupo.

\begin{tabular}{|c|c|c|c|c|}
\hline \multicolumn{5}{|c|}{ DOMÍNIO DAS COMPETÊNCIAS } \\
\hline Descrição das competências & Média $\mu$ & Mediana Md & Moda Mo & Desvio padrão $\sigma$ \\
\hline \multicolumn{5}{|c|}{$\begin{array}{l}\text { C1. Ter conhecimento das normas legais que regulamentam as contratações públicas e a fiscalização de contratos } \\
\text { de terceirização. }\end{array}$} \\
\hline Grupo A & 1,67 & 2 & 2 & 0,577 \\
\hline Grupo B & 2,20 & 2 & 3 & 0,837 \\
\hline \multicolumn{5}{|c|}{ C2. Ter conhecimento das atribuições e responsabilidades inerentes à função de fiscal de contratos. } \\
\hline Grupo A & 2,00 & 2 & Amodal & 1,000 \\
\hline Grupo B & 1,80 & 2 & 1 & 0,837 \\
\hline \multicolumn{5}{|c|}{ C3. Ter conhecimento detalhado do contrato sob sua supervisão e das cláusulas nele estabelecidas. } \\
\hline Grupo A & 2,33 & 2 & 2 & 0,577 \\
\hline Grupo B & 2,80 & 3 & 2 & 0,837 \\
\hline \multicolumn{5}{|c|}{$\begin{array}{l}\text { C4. Registrar, em documento próprio, as irregularidades encontradas e as providências determinadas, decorrentes } \\
\text { do descumprimento das obrigações pactuadas em contrato. }\end{array}$} \\
\hline Grupo A & 1,00 & 1 & Amodal & 1,000 \\
\hline Grupo B & 2,20 & 2 & 2 & 1,483 \\
\hline \multicolumn{5}{|c|}{$\begin{array}{l}\text { C5. Utilizar mecanismos de controle (documentos padronizados) que possam auxiliar no acompanhamento dos } \\
\text { contratos. }\end{array}$} \\
\hline Grupo A & 1,00 & 1 & Amodal & 1,000 \\
\hline Grupo B & 1,40 & 2 & 2 & 0,894 \\
\hline
\end{tabular}

Fonte: resultado da pesquisa. 
experiências com os fiscais que exercem a função há menos tempo.

Finalizando a pesquisa de campo, foi apresentada aos entrevistados uma lista estruturada de desafios, na qual cada participante assinalou, dentre as opções, os três fatores que mais interferiam no desempenho das atividades de fiscal de contratos. A frequência de cada resposta encontra-se disposta na tabela 7 :

Os dados da tabela 7 revelam que os profissionais consideraram a falta de treinamento e qualificação como maior desafio durante a atividade de fiscalização, alcançando o índice de $29 \%$ de ocorrência. De acordo com Alves (2004), o fiscal designado deve possuir perfil ajustado ao ofício delegado, conhecimento técnico e perfeitas condições de analisar, avaliar e controlar eficazmente o instrumento contratual. Sob esse aspecto, é papel da Administração Pública oferecer treinamentos específicos de forma intensa e contínua, visando amenizar as fragilidades sinalizadas pelos profissionais.

$\mathrm{O}$ item "desconhecimento acerca de ferramentas de gestão do conhecimento" surge como o segundo maior desafio relacionado, obtendo o percentual de $25 \%$ das citações. O índice sinaliza a intenção dos fiscais de aplicarem os conceitos e ferramentas de gestão do conhecimento que estiverem à sua disposição

Tabela 6. Índice de Prioridade de Treinamento e ranking de prioridade de capacitação por grupo.

\begin{tabular}{|c|c|c|c|c|}
\hline \multicolumn{2}{|c|}{ GRUPO A } & \multirow{2}{*}{$\begin{array}{l}\text { ÍNDICE DE PRIORIDADE DE TREINAMENTO } \\
\text { (IPT) } \\
\text { COMPETÊNCIAS }\end{array}$} & \multicolumn{2}{|c|}{ GRUPO B } \\
\hline Ranking & Média IPT $\left(\mu_{A}\right)$ & & Média IPT $\left(\mu_{\mathrm{B}}\right)$ & Ranking \\
\hline $3^{\circ}$ & 8,67 & $\begin{array}{l}\text { C1. Ter conhecimento das normas legais que regulamentam } \\
\text { as contratações públicas e a fiscalização de contratos de } \\
\text { terceirização. }\end{array}$ & 6,60 & $4^{\circ}$ \\
\hline $4^{\circ}$ & 7,67 & $\begin{array}{l}\text { C2. Ter conhecimento das atribuições e responsabilidades } \\
\text { inerentes à função de fiscal de contratos. }\end{array}$ & 8,40 & $2^{\circ}$ \\
\hline $5^{\circ}$ & 5,67 & $\begin{array}{l}\text { C3. Ter conhecimento detalhado do contrato sob sua } \\
\text { supervisão e das cláusulas nele estabelecidas. }\end{array}$ & 4,80 & $5^{\circ}$ \\
\hline $1^{\mathrm{o}}$ & 11,33 & $\begin{array}{l}\text { C4. Registrar, em documento próprio, as irregularidades } \\
\text { encontradas e as providências determinadas, decorrentes } \\
\text { do descumprimento das obrigações pactuadas em contrato. }\end{array}$ & 6,80 & $3^{\circ}$ \\
\hline $2^{\circ}$ & 10,67 & $\begin{array}{l}\text { C5. Utilizar mecanismos de controle (documentos } \\
\text { padronizados) que possam auxiliar no acompanhamento } \\
\text { dos contratos. }\end{array}$ & 10,00 & $1^{\mathrm{o}}$ \\
\hline
\end{tabular}

Fonte: resultado da pesquisa.

Quadro 2. Necessidade de aprimoramento de competência por grupo.

\begin{tabular}{|l|c|c|}
\hline \multicolumn{1}{|c|}{ COMPETÊNCIAS } & \multicolumn{1}{c|}{ GRUPOS } \\
\cline { 2 - 3 } & A & B \\
\hline $\begin{array}{l}\text { C1. Ter conhecimento das normas legais que regulamentam as contratações públicas e a fiscalização } \\
\text { de contratos de terceirização. }\end{array}$ & X & \\
\hline C2. Ter conhecimento das atribuições e responsabilidades inerentes à função de fiscal de contratos. & & $\mathbf{X}$ \\
\hline C3. Ter conhecimento detalhado do contrato sob sua supervisão e das cláusulas nele estabelecidas. & & - \\
\hline $\begin{array}{l}\text { C4. Registrar, em documento próprio, as irregularidades encontradas e as providências determinadas, } \\
\text { decorrentes do descumprimento das obrigações pactuadas em contrato. }\end{array}$ & $\mathbf{X}$ & - \\
\hline $\begin{array}{l}\text { C5. Utilizar mecanismos de controle (documentos padronizados) que possam auxiliar no } \\
\text { acompanhamento dos contratos. }\end{array}$ & $\mathbf{X}$ & $\mathbf{X}$ \\
\hline
\end{tabular}

${ }^{1}$ Nenhum dos dois grupos necessita de aprimoramento na competência C3. Fonte: resultado da pesquisa.

Tabela 7. Frequência dos desafios que mais interferem no exercício da função de fiscal de contratos.

\begin{tabular}{lcc}
\hline \multicolumn{1}{c}{ Desafios } & f & fr (\%) \\
\hline Falta treinamento e qualificação para o exercício da função & 7 & $29 \%$ \\
Desconhecimento acerca de ferramentas GC & 6 & $25 \%$ \\
Desconhecimento das atribuições e responsabilidades & 5 & $21 \%$ \\
Desconhecimento acerca da legislação & 3 & $13 \%$ \\
Relacionamento com preposto & 2 & $8 \%$ \\
Desconhecimento de cláusulas contratuais & 1 & $4 \%$ \\
Total & $\mathbf{2 4}$ & $\mathbf{1 0 0 \%}$ \\
\hline
\end{tabular}

Fonte: resultado da pesquisa. 
na tentativa de melhorar seu desempenho em suas atividades. Cumpre esclarecer que a apresentação e definição dessas ferramentas, extraídas de Batista (2012), foi feita no próprio questionário aplicado.

A pesquisa de campo permitiu identificar, a partir da percepção dos fiscais de contratos, os principais desafios enfrentados por esses profissionais durante o desempenho de sua função, além de diagnosticar fragilidades frente às atribuições pertinentes e às legislações que disciplinam o tema contratações públicas.

\subsection{Mecanismos de aprendizagem associados à atividade de fiscalização}

As capacitações anteriormente referidas não são suficientes para criar entre os fiscais, cujo grupo não possui nenhuma estrutura orgânica, $o$ ambiente voltado a aprendizagem requerido para fazer frente aos desafios. É necessário, antes, estimular um processo de interação entre os fiscais, ao modo de uma comunidade de prática, conforme sugerido por Brown \& Duguid (1991) e em sintonia com os mecanismos e processos de aprendizagem defendidos por Figueiredo (2009).

Contemplando-se a metodologia proposta por Figueiredo (2009), foram pontuados alguns importantes processos intraorganizacionais especificamente voltados à atividade de fiscalização. Os dados obtidos através de análise documental e observação direta permitiram identificar a presença ou ausência de comportamentos orientados à aprendizagem organizacional, sendo possível, a partir de critérios preestabelecidos, mensurar o grau das características-chave frente aos mecanismos de aprendizagem diagnosticados. O quadro 3 sintetiza as informações:

Os resultados apresentados no quadro 3 informam que ações ainda precisam ser implementadas na instituição com o intuito de estimular a integração entre os mecanismos de aprendizagem e melhorar a avaliação dos processos. Disponibilizar mecanismos de aquisição e conversão do conhecimento, levando em consideração aspectos definidos por Figueiredo (2009) no que tange à variedade, intensidade, funcionamento e interação, configura o marco inicial para reverter o panorama atual.

\section{Considerações finais}

$\mathrm{O}$ artigo evidenciou as fragilidades presentes nas rotinas operacionais dos fiscais de contratos que atuam em uma universidade pública. Ao consolidar a contribuição do arcabouço teórico da aprendizagem organizacional no entendimento e formulação de propostas de intervenção na área da fiscalização, o trabalho avança na compreensão epistemológica da atividade, trazendo o ferramental da gestão do conhecimento, que embora utilizado em algumas fases e etapas do processo gerencial não apresenta registros de sua utilização no ambiente pesquisado.

Quadro 3. Processos intraorganizacionais voltados à atividade de fiscalização - Período: 2007-2013.

\begin{tabular}{|l|c|c|c|c|}
\hline \multicolumn{1}{|c|}{\begin{tabular}{c}
\multicolumn{1}{|c}{$\begin{array}{c}\text { Processos/mecanismos de } \\
\text { aprendizagem }\end{array}$} \\
\cline { 2 - 5 }
\end{tabular}} & $\begin{array}{c}\text { Variedade } \\
\text { Ausente Presente } \\
\text { (Limitada } \\
\text { Moderada } \\
\text { Diversa) }\end{array}$ & $\begin{array}{c}\text { Características-chave dos processos de aprendizagem } \\
\text { Intermitente } \\
\text { Contínuo }\end{array}$ & $\begin{array}{c}\text { Funcionamento } \\
\text { Interação } \\
\text { Moderado Bom } \\
\text { Excelente }\end{array}$ & $\begin{array}{c}\text { Moderada } \\
\text { Forte }\end{array}$ \\
\hline Período & $\mathbf{2 0 0 7 - 2 0 1 3}$ & $\mathbf{2 0 0 7 - 2 0 1 3}$ & $\mathbf{2 0 0 7 - 2 0 1 3}$ & $\mathbf{2 0 0 7 - 2 0 1 3}$ \\
\hline $\begin{array}{l}\text { [1] Participação em eventos externos: } \\
\text { cursos, palestras e congressos } \\
\text { voltados à fiscalização de contratos. }\end{array}$ & Limitada & Intermitente & Insatisfatório & Fraca \\
\hline $\begin{array}{l}\text { [1] Consulta/assinatura de periódicos } \\
\text { relacionados à prática de fiscalização. }\end{array}$ & Limitada & Contínuo & Moderado & Moderada \\
\hline $\begin{array}{l}\text { [2] Programas internos de } \\
\text { treinamento abordando tema } \\
\text { fiscalização de contratos. }\end{array}$ & Limitada & Intermitente & Insatisfatório & Fraca \\
\hline $\begin{array}{l}\text { [3] Compartilhamento de experiências } \\
\text { e conhecimentos envolvendo práticas } \\
\text { de fiscalização. }\end{array}$ & Limitada & Intermitente & Moderado & Moderada \\
\hline $\begin{array}{l}\text { [3] Reuniões para solução conjunta de } \\
\text { problemas. }\end{array}$ & Moderada & Contínuo & Bom & Forte \\
\hline $\begin{array}{l}\text { [4] Manual de procedimentos } \\
\text { apresentando orientações de boas } \\
\text { práticas de fiscalização. }\end{array}$ & Ausente & Insatisfatório & Fraca \\
\hline
\end{tabular}

Legenda: [1] Aquisição externa de conhecimento; [2] Aquisição interna de conhecimento; [3] Socialização de conhecimento;

[4] Codificação de conhecimento; Fonte: adaptado de Figueiredo (2009). 
A partir da percepção dos entrevistados ficou demonstrado que a instituição em estudo disponibiliza de maneira pouco satisfatória mecanismos de aprendizagem voltados à atividade de fiscalização de contratos. A maioria dos fiscais não realiza nenhum registro de conhecimento durante o desempenho da função e poucos utilizam mecanismos de controle para auxiliar no acompanhamento dos contratos de serviços terceirizados. A ausência da codificação, além de prejudicar a disseminação do conhecimento, traduz de forma negativa o acompanhamento dos termos pactuados e interfere diretamente na eficiência operacional dos profissionais.

Os fiscais de contrato na organização estudada não constituem por si só um grupo organicamente estruturado, com objetos idênticos e cultura assemelhada, sobre o qual se possa implementar facilmente as ações de capacitação formais. Eles funcionam muito mais como uma comunidade de prática, a qual tem um papel fundamental na garantia da qualidade e na defesa e preservação do escopo dos serviços contratados. Portanto, constituem um locus privilegiado da ação organizacional que, se operado em conjunto com um processo de licitação bem feito, pode resultar em ganhos econômicos e sociais.

Diante do atual cenário, marcado por fragilidades no campo da fiscalização de contratos, torna-se imprescindível intensificar ações de incentivo à capacitação, no intuito de aprimorar os processos internos de trabalho, desenvolver competências profissionais e disponibilizar adequação técnica aos agentes públicos. São muitos os deveres e exigências, tanto explícitas quanto tácitas, inerentes ao exercício da atividade e, para tanto, os fiscais precisam estar preparados, treinados, e, acima de tudo, dispostos a desenvolver uma cultura de fiscalização e controle contínuo dos contratos que supervisionam.

Finalmente, como aprofundamento dos insights aqui produzidos, sugere-se que estudos futuros se encarreguem, por um lado, de estreitar os vínculos e as conexões epistemológicas entre a atividade de fiscalização de contratos, com sua heterogeneidade e contingência, e a gestão do conhecimento, com seu desafio de ultrapassar a mera gestão dos tangíveis, incorporando pessoas com toda a idiossincrasia e complexidade que isso significa. E, por outro lado, cabe o aprofundamento do quadro teórico e empírico que situe adequadamente a esfera do público, na qual mudanças pontuais se inserem, impactando e sendo impactadas pelo contexto cultural, político e motivacional que esse público engendra.

\section{Agradecimentos}

Os autores agradecem aos revisores que gentilmente aportaram contribuições relevantes para a construção final do trabalho.

\section{Referências}

Almeida, C. W. L. (2009). Fiscalização contratual: "Calcanhar de aquiles" da execução dos contratos administrativos. Revista do Tribunal de Contas da União, 114, 53-62

Alves, L. S. (2004). Gestão e fiscalização de contratos públicos. Revista do Tribunal de Contas da União, 102, 60-69.

Andrade, M. T. T., Ferreira, C. V., \& Pereira, H. B. B (2010). Uma ontologia para a Gestão do Conhecimento no Processo de Desenvolvimento de Produto. Gestão \& Produção, 17(3), 537-551.

Batista, F. F. (2006). O desafio da gestão do conhecimento nas áreas de Administração e Planejamento das Instituições Federais de Ensino Superior (IFES) (Texto para discussão, 1181). Brasília: IPEA. Recuperado em 25 de setembro de 2013, de www.ipea.gov.br.

Batista, F. F. (2012). Modelo de gestão do conhecimento para a administração pública brasileira: como implementar a gestão do conhecimento para produzir resultados em beneficio do cidadão. Brasília: IPEA. Recuperado em 25 de setembro de 2013, de www.ipea.gov.br

Battaglio, R. P. Jr, \& Ledvinka, C. B. (2009). Privatizing human resources in the public sector. Review of Public Personnel Administration, 29(3), 293-307. http://dx.doi. org/10.1177/0734371X09338898.

Borges-Andrade, J. E., \& Lima, S. M. V. (1983). Avaliação de necessidades de treinamento: um método de análise de papel ocupacional. Tecnologia Educacional, 12(54), 5-14.

Brasil. (1993, 22 de Junho). Lei no 8.666, de 21 de junho de 1993. Regulamenta o art. 37, inciso XXI da Constituição Federal, institui normas para licitações e contratos da Administração Pública e dá outras providências. Brasília, DF: Diário Oficial da República Federativa do Brasil. Recuperado em 12 de setembro de 2013, de http://www. planalto.gov.br/ccivil_03/Leis/L8666cons.htm

Brasil. Ministério do Planejamento, Orçamento e Gestão. Secretaria de Logística e Tecnologia da Informação. (2008, 23 de maio). Instrução Normativa $n^{\circ} 02$, de 30 de abril de 2008. Dispõe sobre regras e diretrizes para a contratação de serviços continuados ou não. Brasília, DF: Diário Oficial da República Federativa do Brasil. Recuperado em 20 de outubro de 2013, de http://www. comprasnet.gov.br/legislacao/in/in02_30042008.htm.

Brown, J. S., \& Duguid, P. (1991). Organizational learning and communities-of-practice: toward a unified view of working, learning and innovation. Organization Science, 2(1), 40-57. Recuperado em 15 de setembro de 2013, de http://citeseerx.ist.psu.edu/viewdoc/download?doi=10.1 1.530.7851\&rep=rep1\&type $=$ pdf

Carbone, P. P.; Brandão, H. P., Leite, J. B. D., \& Vilhena, R. M. P. (2009). Gestão por competências e gestão do conhecimento. $3 \mathrm{a}$ ed. Rio de Janeiro: Editora FGV.

Carvalho, C. P., \& Gomes, R. S. (2012). Gestão do conhecimento como vertente de sustentabilidade organizacional. In Anais do VIII Congresso Nacional de Excelência em Gestão Rio de Janeiro: UFF.

Cherman, A.; Rocha-Pinto, S. R. (2016). Valoração do conhecimento nas organizações: as concepções dos 
indivíduos no contexto do trabalho. Revista Organizações \& Sociedade, 23(77), 307-328.

Choo, C. W. (2006). A organização do conhecimento: como as organizações usam a informação para criar significado, construir conhecimento e tomar decisões. São Paulo: Editora SENAC.

Christopher, D., \& Tanwar, A. (2012). Knowledge management in outsourcing environment: people empowering people. IUP Journal of Knowledge Management, 10(2), 61-86.

Durand, T. (1998). Forms of incompetence. In Proceedings of IV International Conference on Competence-Based Management. Oslo: Norwegian School of Management.

Easterby-Smith, M., \& Prieto, I. M. (2008). Dynamic capabilities and knowledge management: an integrative role for learning? British Journal of Management, 19(3), 235249. http://dx.doi.org/10.1111/j.1467-8551.2007.00543.x.

Figueiredo, P. N. (2009). Gestão da inovação: conceitos, métricas e experiências de empresas no Brasil. Rio de Janeiro: LTC.

Finger, M., \& Brand, S. B. (2001). Conceito de "Organização de Aprendizagem" aplicado à Transformação do Setor Público: Contribuições Conceituais ao Desenvolvimento da Teoria. In M. Easterby-Smith et al. (Org.), Aprendizagem organizacional e organização de aprendizagem: desenvolvimento na teoria e na prática (pp. 165-195). São Paulo: Atlas.

Fleury, M. T. L., \& Fleury, A. (2001). Construindo o conceito de competência. Revista de Administração Contemporânea, 5(n.spe), 183-196.

Freitas, M., \& Maldonado, J. M. S. V. (2013). O pregão eletrônico e as contratações de serviços contínuos. Revista de Administração Pública - RAP, 47(5), 1265-1281.

Gonçalves, L. A. E. B. (2006). Sistema de Controle da Terceirização na Universidade Federal do Rio Grande do Sul (Dissertação de mestrado). Universidade Federal do Rio Grande do Sul, Porto Alegre. 96 f.

Lemos, B., \& Joia, L. A. (2012). Fatores relevantes à transferência de conhecimento tácito em organizações: um estudo exploratório. Gestão \& Produção, 19(2), 233-246.

Liu, S., \& Deng, Z. (2015). Understanding knowledge management capability in business process outsourcing: a cluster analysis. Management Decision, 53(1), 124-138. http://dx.doi.org/10.1108/MD-04-2014-0197.

Lopes, M. C., Fialho, F. A. P., Lopes, J. F., Ribeiro, S. F. \& Wilhelm, P. P. H. (2010). Análise da relação entre aptidões cerebrais e competências gerenciais: o caso de uma empresa têxtil. Gestão \& Produção, 17(1), 123-136.

Marinho, R. C. P., \& Andrade, E. P. (2013a). Gestão do conhecimento como recurso estratégico para o desenvolvimento de competências: estudo de caso em uma universidade pública. In Anais do IX Congresso Nacional de Excelência em Gestão. Rio de Janeiro: UFF.

Marinho, R. C. P., \& Andrade, E. P. (2013b). Fiscalização de contratos em universidade pública: fazendo confluir manual de procedimentos de controle e gestão do conhecimento. In Anais do IX Encontro Mineiro de Engenharia de Produção. Juiz de Fora: UFJF.
Marinho, R. C. P., \& Andrade, E. P. (2013c). Mecanismos de aprendizagem associados à atividade de fiscalização de contratos: estudo de caso em uma universidade pública. In Anais do IV Encontro Fluminense de Engenharia de Produção, Volta Redonda: UFF.

Oliveira, O. B., \& Villardi, B. Q. (2012). Práticas de aprendizagem coletiva de pesquisadores de uma empresa de conhecimento intensivo: características, obstáculos e implicações para a formação de comunidades de prática. In Anais do XXXVI Encontro da Associação Nacional de Pós-Graduação e Pesquisa em Administração. Rio de Janeiro: Anpad.

Organisation for Economic Co-operation and Development - OECD (2004). Public sector modernisation: governing for performance. Paris: OECD Observer. Recuperado em 15 de dezembro de 2016, de http://www.oecd.org/site/ govgfg/39044817.pdf.

Picoli, F. R.; Takahashi, A. (2016). Capacidade de absorção, aprendizagem organizacional e mecanismos de integração social. Revista de Administração Contemporânea, 20(1), 1-20.

Pinto, R. L. (2009). Qualidade no serviço de manutenção predial terceirizado: um estudo de caso em uma organização pública autárquica (Tese de doutorado). Universidade de São Paulo, São Paulo. 318 f.

Rodriguez, M. V. R. Gestão do conhecimento e inovação nas empresas. Rio de Janeiro: Qualitymark Editora Ltda, 2010.

Santos, J. L. S., Steil, A. V., \& Varvakis, G. (2012). O Processo de Aprendizagem Organizacional durante o Planejamento Estratégico em uma Universidade Pública Brasileira. In Anais do XXXVI Encontro da Associação Nacional de Pós-graduação e Pesquisa em Administração. Rio de Janeiro: Anpad

Serenko, A., \& Bontis, N. (2016). Negotiate, reciprocate, or cooperate? The impact of exchange modes on interemployee knowledge sharing. Journal of Knowledge Management, 20(4), 687-712. http://dx.doi.org/10.1108/ JKM-10-2015-0394.

Tribunal de Contas do Estado de Mato Grosso - TCE-MT. (2015). Fiscalização de Contratos Administrativos. Cuiabá: Publicontas. 134 p. Recuperado em 19 de novembro de 2016, de https://ead.tce.mt.gov.br/theme/bcu/gestor/ Fiscal_de_contratos_Adm.pdf

Vera, D., \& Crossan, M. (2005). Organizational learning and knowledge management: toward an integrative framework. In M. Easterby-Smith \& M. Lyles (Org.). Handbook of Organizational Learning and Knowledge Management Malden: Blackwell.

Vergara, S. C. (2007). Projetos e relatórios de pesquisa em administração. (9a ed.) São Paulo: Atlas.

Vieira, A. P., Vieira, H. P., Furtado, M. R. \& Furtado, M. R. R. (2010). Gestão de contratos de terceirização na administração pública: teoria e prática (4a ed.) Belo Horizonte: Editora Fórum.

Yin, R. K. (2005). Estudo de caso, planejamento e métodos. (3a ed.). Porto Alegre: Bookman. 